Anuario Latinoamericano Ciencias Políticas

y Relaciones Internacionales

vol. 8, 2019

pp. $237-261$

\section{Polemizar y controvertir lo incuestionable. Deconstruir conceptos estáticos mediante nuestra historia personal}

\section{Polemicizing and Controverting What Is Unquestionable. The Deconstruction of Static Concepts Through Our Personal History}

\author{
Florencia Di Giorgio* \\ INDEPENDENT RESEARCHER \\ $\triangle$ dgiorgioflorencia@gmail.com \\ https://orcid.org/0000-0001-8163-1784
}

\title{
RESUMEN
}

Cuando J. Butler reflexionaba sobre la performatividad del género, nos introdujo en una forma novedosa de comprender la subjetividad sexo genérica, permitiéndonos ver el sesgo que pesa sobre nuestras percepciones a raíz de las normas reguladoras que imperan a nivel social. Siguiendo esta línea, y a partir del estudio de caso de Tahiana Marrone, una excombatiente de la Guerra de Malvinas, este trabajo buscará reflexionar sobre la construcción de los roles socioculturales mediante la asignación necesaria de los mismos a un género, haciendo hincapié específicamente en el concepto hegemónico de "veterano de Guerra de Malvinas".

PALABRAS CLAVE: veteranx de guerra, intersexual, género, redefinición, reconstrucción.

\section{ABSTRACT}

When J. Butler reflected on the performativity of gender, she introduced us to a new way of understanding the sex and gender identity, allowing us to see the bias that weighs on our perceptions as a result of the regulatory norms that prevail at a social level. Following this line, and basing our study on the case of Tahiana Marrone,

Miembro de la Red Federal de Investigadores sobre la Cuestión Malvinas ReFEM 2065 - Laboratorio de Políticas Públicas hacia la Cuestión Malvinas, investigadora junior. Miembro del Centro de Estudios de Género(s) y Relaciones Internacionales en el Instituto de Relaciones Internacionales. Licenciada en Ciencia Política y Relaciones Internacionales. 
Dossier América Latina: género y política a former Malvinas War veteran, this work will seek to reflect on the construction of sociocultural roles through the necessary assignment of them to a specific gender, emphasizing on the hegemonic concept of "Malvinas War Veteran".

KEYWORDS: war veterans, intersexual, gender, redefinition, reconstruction.

\section{Introducción}

¿Quiénes somos? es una pregunta que siempre, tal vez en algunos momentos más que otros, nos realizamos. Una pregunta con respuestas sumamente flexibles que definimos en cada emoción, pensamiento y acción que realizamos. Pero en ese dificultoso ejercicio que es la autodefinición, existen un par de respuestas inmediatas que solemos emitir: nuestro nombre, nuestra edad, nuestro sexo.

El análisis planteado por este trabajo versará sobre la construcción producida en torno a la última de las etiquetas nombradas. Una construcción que, debido a la acción de agentes de naturaleza diversa (sociales, culturales y hasta individuales), moldea nuestra identidad llevándonos a una asociación necesaria (aunque errónea) de nuestro sexo asignado al nacer con nuestro género autopercibido.

Instrumentos con una incidencia tal que podemos rastrear su acción incluso al momento de la gestación, cuando una de las incógnitas que usualmente desean responder quienes ocupan el rol de padres es si ese futuro bebé será varón o mujer, derivando dicha definición únicamente del sexo biológico de aquel.

La cuestión recae en que, a partir de dicha definición primigenia, se llevará adelante una crianza y socialización del niño o la niña en la cual su subjetividad será encauzada y, en dicho proceso, censurada, para responder a determinados estereotipos construidos en torno a lo que ser "mujer" u "hombre" implica, generándose una categorización a partir de la cual la autopercepción de la persona sobre sí misma se basará en una comprensión restringida de su ser.

Pero desde hace tiempo ya, estas estructuras están siendo cuestionadas por una simple razón: el ser humano es tan amplio que no puede ser encasillado en un simple binarismo que encuentra sus raíces simplemente en nuestros genitales, razón por la cual se vuelve más idóneo hablar del género de una persona a la hora de definir su identidad, más que de su sexo. Es así que paulatinamente estamos siendo testigos de la irrupción de cuerpos y subjetividades que no se circunscriben al marco de comprensión binario, heteronormado y cisexista, que con su realidad polemizan dicha estructura. Por un lado, al ser ejemplos vivos del error cometido en la asociación directa y necesaria del género de la persona a su sexo biológico y, por el otro, al representar existencias tan plurales que demuestran lo restringido y arcaico de perpetuar la idea de asociar el cumplimiento de roles sociales al género de la persona. 
A su vez, veremos también cómo podemos abordar esta temática tan amplia y compleja como es la reducción de la identidad de género de una persona a razones biológicas reflejadas en su sexo, sin tener en cuenta el resto de las dimensiones que afectan y construyen la identidad de un ser humano como son su emocionalidad o su dimensión psicológica, desde otra perspectiva también sumamente compleja como es la visibilización, es decir, la adquisición de entidad, realidad, reconocimiento y aceptación por parte de la sociedad de los diferentes colectivos considerados minoritarios o relegados en un entorno que, desde sus inicios, se ha construido sobre la base de una estructura de dominación machista (Bourdieu, 1999), heteronormada y etnocentrista con supremacía del hombre blanco heterosexual.

Para argumentar lo anteriormente expuesto respecto a la construcción de roles asociados al género, en donde no sólo se produce una tensión cuando dentro de la ecuación binaria hombre - mujer los mismos rompen con aquellos roles, sino que, la irrupción de los cuerpos e identidades que no responden a la lógica heteronormada y cis sexual también vienen a cuestionar esta asignación reproducida en el marco de la sociedad patriarcal, apoyaremos nuestro análisis en el estudio de caso de Tahiana Marrone. Ella es una ${ }^{1}$ soldado excombatiente de la Guerra de Malvinas quien hace apenas unos pocos años decidió exteriorizar quien realmente es y comenzar a vivir su vida como ella, como Tahiana, dejando atrás un pasado que la reconocía como Osvaldo Marrone.

Pero, además, Tahiana no sólo es parte de un colectivo minoritario dentro de la sociedad en general (en su caso es transexual e intersexual ${ }^{2}$ ) que reclama por sus derechos y por lograr finalmente la equidad que tan postergada se encuentra. Sino que, además, ella misma conforma una minoría o, mejor dicho, un caso único dentro del grupo conformado por los veteranos de la Guerra de Malvinas. Dado que es el único caso de un veterano o veterana que ha asumido públicamente una identidad de género diferente a las correspondientes al binarismo hombre/mujer.

Tomaremos como prototipo de base la construcción del rol del veterano de la Guerra de Malvinas, el cual responde en el ideario general promedio a una serie de premisas arraigadas socialmente, para analizar cómo en el úl-

1 Es pertinente aclarar que utilizaré este pronombre para referirme a Tahiana como excombatiente, más allá de que la transición realizada de hombre a mujer se haya producido hace pocos años por lo cual ella vivió como excombatiente masculino la mayor parte del tiempo. No obstante, en respeto de su autopercepción considero que lo más apropiado es utilizar el pronombre femenino.

2 La intersexualidad no se refiere ni a la identidad de género, ni a la orientación sexual de la persona. Por lo tanto, una persona intersexual puede considerarse hombre y tener preferencias sexuales por otros hombres, o que su identidad sea de mujer y tener interés por hombres, etc. Por ejemplo, Tahiana es una mujer intersexual que atravesó el proceso de transformación de hombre a mujer y su preferencia sexual va dirigida a los hombres por lo que se describe como una mujer heterosexual.
Polemizar y controvertir lo incuestionable. Deconstruir conceptos estáticos mediante nuestra historia personal

Florencia Di Giorgio 
Dossier América Latina: género y política timo tiempo han irrumpido en el escenario público diversos casos que cuestionan dicha construcción. Uno de ellos son las mujeres y el otro es el caso de Tahiana ${ }^{3}$.

Surge así la necesidad de abordar otra arista dentro del entramado que implica su vida en sí, que es el cómo entender a la Tahiana veterana de guerra actual a partir del Osvaldo del pasado que luchó en la guerra ¿Estamos ante la presencia de un veterano de guerra o de una veterana? ¿será necesario reconocerla oficialmente como veterana? ¿cómo fue recibida por sus compañeros esta transformación personal que encaró? Si entendemos que ella se sintió siempre una mujer, aunque haya luchado siendo biológicamente hombre ¿implica esto un cambio en la perspectiva de que la "guerra es cosa de hombres"? ¿la sociedad la aceptará de la misma manera que lo hizo cuando era hombre?; es decir, ¿seguirán respetándola como veterana al igual que cuando era Osvaldo? ¿cómo debemos referirnos a su persona? ¿debemos respetar el corte temporal o utilizar el apelativo femenino tanto para referirnos a ella en el pasado cuando era Osvaldo como en el presente siendo Tahiana? Todas estas preguntas son una manifestación de las diversas interrogantes y polémicas que se producen a la hora de buscar comprender el reconocimiento respecto a la nueva realidad que se plantea con el caso de Tahiana.

A partir de esta tensión producida en lo que implica la construcción de la representación hegemónica del veterano de guerra de Malvinas, observamos la existencia de tensiones inherentes que se generan en la deconstrucción de aquella debido a las diversas lógicas que toman quienes buscan ser consideradas dentro de este rol. Tensiones que se observan en diferentes planos, a saber, en términos legales, en cuanto a la aprehensión y el reconocimiento social de los mismos, y respecto a las reflexiones que surgen al tener en cuenta que el estudio de caso del cual partimos posee una singularidad inherente, que es la transición respecto a su identidad de género.

Por último, este análisis también nos llevará, casi necesariamente, a reflexionar sobre lo planteado inicialmente respecto a cómo dentro de una estructura basada en una lógica heteronormada, androcentrista y cisexista existe un estereotipo construido para cada género dentro del binario hombre - mujer cis.

\section{La historia de Tahiana}

Antes de entrar de lleno en la reflexión a la cual nos llama este trabajo, será pertinente presentar el estudio de caso al cual haremos referencia. Tahiana Marrone, hoy con 53 años, no fue siempre aquella mujer que hoy se muestra libremente ante la sociedad. O, mejor dicho, siempre lo fue, pero hace tan sólo

3 Distinción realizada sólo con fines analíticos. Tahiana Marrone es una mujer dado que así se autopercibe y ha llevado adelante una transición para exteriorizar su identidad como tal. La diferencia marcada hace alusión a las mujeres cis que participaron de la guerra como parte del cuerpo sanitario y Tahiana que como veterana es una mujer trans. 
unos pocos años se animó a dar el gran paso de dejar atrás la identidad e imagen de Osvaldo Marrone para abrazar a Tahiana y permitirle salir al mundo.

La mujer que inspira esta investigación es veterana de la Guerra de Malvinas. Fue a las islas como Osvaldo Marrone, con 17 años, cumpliendo allí los 18. Formó parte del Batallón de Ingenieros $\mathrm{N}^{\circ} 9$ y estuvo en la Bahía de Fox. Pero esta no fue la única gran lucha que tuvo que atravesar en su vida, porque desde siempre, o al menos desde que tiene consciencia, sintió que su verdadera identidad, su verdadero yo, no era el que mostraba al mundo; para expresarlo de manera simple, siempre se sintió mujer, pero tuvo que vivir una vida (impuesta) como hombre.

La raíz de aquella identificación con lo femenino que aparentemente sentía pero que no podía explicar, fue descubierta hace tres años (2015 aproximadamente) cuando al realizarse un estudio genético descubrió que tiene el Síndrome de Klinefelter por el cual posee un $78 \%$ de cromosomas X (femeninos) y un $22 \%$ de cromosomas Y (masculinos), a razón de lo cual biogenéticamente es "más" mujer que varón según sus palabras (Marrone, 2018).

Este resultado sería el punto de quiebre necesario para finalmente dar el paso de permitirse vivir su vida como Tahiana. Una vida que negó por tanto tiempo y producto de la cual se sometió a procedimientos que moldearon y cercenaron su subjetividad y su cuerpo de acuerdo con los parámetros socialmente esperados, sometiéndose desde los 21 años a un tratamiento de testosterona para ser "más hombre" cuando internamente no se sentía como tal.

Este tratamiento de testosterona ${ }^{4}$ le permitió vivir aquella vida que supuestamente se le había presentado como normal, es decir, una vida de hombre; en la que pudo sentirse atraída por mujeres, casarse y hasta tener hijos ${ }^{5}$. Pero un tratamiento que sólo sirvió para esconder quien realmente era, trayéndole, en el medio, hasta problemas de salud por los que tuvo que ser internada.

Nacida en Corral de Bustos (Córdoba), aunque desde hace un tiempo vive en Chañar Ladeado (Santa Fe), que sólo queda a unos kilómetros y ambos son pueblos con pocos habitantes, era muy fuerte el miedo a la exclusión y la condena social que, en ámbitos tan reducidos, puede sentirse mucho más directamente. No obstante, una vez que Tahiana salió al mundo, se encontró con que tales temores eran, tal vez, exagerados, dado que, si bien existen casos de discriminación como en cualquier lado, también logró encontrar aceptación y respeto a su historia y su decisión.

A lo largo de su vida Tahiana recibió de su entorno una crianza y forma de vida que la encasillaba dentro del modelo sexogenérico y orientación sexual masculina - heterosexual, por lo que poder revertir dicha comprensión que

4 Un tratamiento que se configura dentro de las denominadas "tecnologías normalizadoras del cuerpo" de las que habla Beatriz Preciado para hacer referencia a los dispositivos existentes para perpetuar la construcción hegemónica de sexo-cuerpo bajo la normativa heteropatriarcal (Preciado, 2002)

5 No he podido clarificar si pudo tener hijos naturalmente o producto de inseminación artificial.
Polemizar y controvertir lo incuestionable. Deconstruir conceptos estáticos mediante nuestra historia personal

Florencia Di Giorgio 
Dossier América Latina: género y política pesaba sobre ella para reafirmar su verdadera subjetividad implicó romper con una estructura identitaria no sólo personal, sino aquella con la que su entorno la reconocía y aceptaba.

"Si otros me reclaman cuando me afirmo, entonces el género es para otro y proviene de otro antes de convertirse en el mío" (Butler, 2004, p. 34), y es a esto a lo que tuvo que enfrentarse Tahiana. Tuvo que aprehender su verdadera identidad de género, convertirla en propia, rechazando aquella que le había sido impuesta desde su nacimiento, rompiendo con todos los agentes que actuaban bloqueándola y llevando adelante un proceso interno de deconstrucción y redefinición de su autopercepción. Una autopercepción totalmente moldeada de acuerdo con parámetros ajenos.

El costo de hacerlo fue, lamentablemente, alto. En el medio perdió o se quebró la relación con muchos afectos debido a que se negaban a verla como mujer, pesando más los egoísmos personales que el respeto y aceptación hacia quien realmente es Tahiana; porque vivimos en una sociedad donde todavía cuesta dejar de lado las estructuras de pensamiento enquistadas y cercenadoras de la realidad, a raíz de las cuales, cuando algo no encaja con la propia construcción de la realidad, en lugar de buscar la forma de aceptarlo, se antepone el rechazo a lo "desconocido".

No obstante, Tahiana reafirma su decisión y expresa que, a pesar del dolor y los costos que todo esto generó, lo mejor fue haberse animado, finalmente, a vivir la vida como quien verdaderamente es (Marrone, 2018).

\section{Veterano de Guerra de Malvinas. Construcción y deconstrucción}

Cuando hablamos del veterano de Guerra de Malvinas, usualmente el imaginario colectivo tiende a asociarlo con dos tipos de representaciones que, si bien podríamos considerar antagónicas, tienen un punto en común que no es menor. Por un lado, están quienes proyectan la idea de "veterano" como los jóvenes que fueron a luchar a la guerra, con una escasa edad y preparación, temerosos de tener que afrontar obligadamente uno de los peores episodios de su vida, generador de traumas posteriores que los vulneraron y marcaron. Ahora bien, por otro lado, nos encontraremos con quienes, si bien consideran lo anteriormente descripto, también asocian la figura del veterano con la idea de héroes de la patria que, a pesar del miedo, supieron poner el cuerpo valientemente para luchar por una "causa noble".

Pero más allá de esta separación existente en las dos representaciones que aquí describimos de manera general ${ }^{6}$, existe una cuestión en común que las

6 Las descripciones realizadas sobre la representación de la idea del Veterano de la Guerra de Malvinas fueron realizadas de manera genérica, planteándola a grandes rasgos, y no responden a un estudio en profundidad, sino más bien a la percepción de quien escribe. 
une y es que a la hora de bosquejarnos el prototipo de "veterano de guerra" casi involuntariamente tendemos a llevar adelante una asociación en la que representamos la figura de un hombre cis y heterosexual; un hombre que durante su juventud fue a luchar al conflicto en defensa de su patria, con valentía y coraje o bien con temor y fragilidad; que a su retorno tuvo que llevar adelante una lucha personal para lograr el reconocimiento que se le debía y que, con el tiempo, devino una especie de calificación generalizada a nivel discursivo de quienes estuvieron en la guerra como héroes de la patria.

Aquella lucha encarada por los excombatientes, aunque legítima, no será el objetivo de este trabajo; nuestra intención es concentrarnos en el ideario colectivo construido en torno a este rol que, como previamente expliqué, se tiende a asociar directamente con el estereotipo de hombre heterosexual cisgénero.

Precisamente, no es casual que ésta sea la percepción imperante a la hora de pensar este rol, y es que el mismo responde a una construcción que sigue la lógica marcada por la estructura en la que se produce, la cual posee una naturaleza androcentrista y heteronormativa, por la que cualquier persona que no responda a dicha norma encontrará una gran dificultad a la hora de buscar identificarse con la misma.

La construcción de roles asignados al género es un hecho que viene siendo denunciado hace tiempo. En un primer momento fue abordado por la segunda ola del feminismo que, aunque desde una perspectiva restringida, reflexionó profundamente sobre el tema, avocándose sólo al binomio hombre - mujer, buscando romper con la idea construida de mujer como lo frágil, delicado, asociado a lo doméstico y la maternidad.

Más tarde, al entender que este análisis era limitado para abarcar la totalidad de las realidades existentes, surgen las nuevas teorías en el marco de la tercera ola y la teoría queer, cuyo estudio amparó la comprensión de los cuerpos e identidades no encasillados en la heteronormatividad y que rompen totalmente con la idea hegemónica de asignación de roles sociales en torno al género, al desplazar la comprensión de la identidad de género de una persona desde el sexo biológicamente asignado al nacer.

Pero más allá de los análisis teóricos realizados en donde comprendemos esta necesidad de deconstruir los estereotipos y roles en torno al género, así como también la importante evolución que socioculturalmente se ha logrado al encontrarnos con una paulatina aceptación de aquella realidad, aún se encuentran muy arraigadas en la mentalidad individual y social de las personas las ideas construidas de determinados roles sociales producto de una reproducción casi involuntaria de los mismos llevada adelante por las diversas instituciones de socialización, así como también por los diversos instrumentos existentes para moldear nuestros cuerpos e identidades.

Siguiendo a De Lauretis, entenderemos que el género no es algo preexistente en el ser humano, sino que es el producto de "efectos producidos en los cuerpos, los comportamientos y las relaciones sociales, en palabras de
Polemizar y controvertir lo incuestionable. Deconstruir conceptos estáticos mediante nuestra historia personal

Florencia Di Giorgio 
Dossier América Latina: género y política
Foucault, por el despliegue de una tecnología política compleja” (De Lauretis, 1989 , p. 8). De la misma manera, Butler argumenta que el género de una persona es performativo, es decir:

... lo que consideramos una esencia interna del género (lo que consideramos como una manifestación personal y propia), en realidad se construye a través de un conjunto sostenido de actos, postulados por medio de la estilizaci6n del cuerpo basada en el género. De esta forma se demuestra que lo que hemos tornado como un rasgo "interno» de nosotros mismos es algo que anticipamos y producimos... (Butler, 1999, p. 17)

Al comprender entonces que el género de una persona no es dado sino, más bien, construido y moldeado por agentes que esculpen nuestra identidad de acuerdo con su lógica, podremos deducir que los roles asociados al género también son una construcción que responden a dicha tendencia, la cual se basa en premisas orientadas por lo que la intelectual Adrienne Rich denominó "heterosexualidad obligatoria" (Rich, 1980) y lo que Butler denunció como la coincidencia necesaria que plantea este sistema entre sexo - género - deseo - práctica sexual (Butler, 2004) que lleva a aquel "régimen de la heterosexualidad".

Esta "producción de identidades" (Foucault, 1975) por parte de la sociedad ha llevado a clasificar al mundo en términos de lo masculino y lo femenino, estableciendo parámetros y prácticas identificatorias para cada uno a razón de las cuales, si una persona de un determinado sexo lleva a cabo prácticas atribuibles al sexo contrario, inmediatamente entran en acción los métodos disciplinarios para corregir la "desviación". Y de la misma manera sucede cuando nos detenemos a pensar al veterano de Guerra de Malvinas.

En el último tiempo han irrumpido en el escenario público dos grupos que interpelan directamente a aquella percepción hegemónica del veterano de guerra: uno de ellos son las mujeres que participaron de la guerra ${ }^{8}$ y el otro es el estudio de caso que toma este trabajo, la vida de Tahiana Marrone, una excombatiente que luchó en la guerra como Osvaldo Marrone pero que hace unos pocos años llevó adelante la transición para exteriorizar su identidad femenina y manifestarse como mujer.

El gran problema surge cuando, al existir ya una construcción realizada en torno al rol aquí analizado, y dicha perspectiva se ha generalizado y ha sido

7 Concepto acuñado por Adrienne Rich en 1980 para denunciar la ausencia de cuestionamiento del feminismo de la época a la heterosexualidad como otra institución de opresión en la que no se tiene en cuenta todas aquellas manifestaciones sexuales que sean distintas a la heterosexualidad (específicamente ella reflexiona sobre las lesbianas).

8 Nos referimos a las mujeres que participaron en la Guerra de Malvinas como parte del cuerpo sanitario argentino. Para más información: "Las mujeres también fueron parte de la Guerra”. Florencia Di Giorgio, 2016. Disponible en: https://periodicos.ufpe.br/revistas/revsocio/article/view/237056/29417 
aceptada colectivamente, se torna difícil romper con aquello para que las nuevas realidades que se identifican con el mismo sean comprendidas a la par de quienes responden a la concepción tradicional del concepto. Al no responder a la serie de caracteres por los cuales se define dicho rol, y si los mismos se plantean de manera estanca e imposibles de ser redefinidos, los nuevos actores o actrices que reclaman ser parte del mismo serán víctimas de una invisibilización en diferentes planos.

Vuelvo a tomar este concepto, planteado por Jean Claude Bourdin, quien lo define como "una categoría hermenéutica que se hace cargo de la interpretación de un fenómeno contradictorio que consiste en existir, en ser-ahí y, al mismo tiempo, en no ser visto/percibido u oído/escuchado [cuya] percepción está condicionada por marcos sociales" (Bourdin, 2010). Tal como lo manifiesta el autor, la persona es, tiene una entidad, pero es / existe en un ambiente que lo excluye y únicamente lo aceptará como parte si se adecúa a los patrones socialmente aceptados y demarcados por las prácticas legitimadas.

Se nos presenta entonces una tensión inherente en la percepción hegemónica del "vterano de Malvinas" debido a estas nuevas realidades que sacuden los preceptos en torno a los cuales el mismo se había construido. Entendemos que, como todo rol social, el mismo no se define únicamente por cuestiones legales, sino que (y así fue planteado al inicio de este inciso cuando se realizó la primigenia definición) es producto de diversos factores que inciden a la hora de percibir y personificar de manera estandarizada la figura del veterano.

En consecuencia, los diversos casos que fueron surgiendo encontrarán en su objetivo de ser reconocidos dentro del colectivo de "veterano/veterana de la Guerra de Malvinas" diversas trabas y dificultades consustanciales a la naturaleza de su reclamo; es decir, no es igual la lógica de la búsqueda por el reconocimiento encarado por las mujeres que fueron parte de la guerra, que la dialéctica que tomará la redefinición del reconocimiento como veterano/ veterana de Tahiana Marrone, quien ya cuenta con un legítimo reconocimiento (y con legítimo me refiero a reconocido no sólo legalmente, sino también socioculturalmente) el cual responde a su vida como Osvaldo Marrone.

\section{Veteranx intersexual ${ }^{9}$}

La historia de Tahiana Marrone como excombatiente de la Guerra de Malvinas que llevó adelante una transición de hombre a mujer por la cual adoptó una identidad de género femenina y una exteriorización de esta como tal, plantea la necesidad de reflexionar no sólo respecto a las implicancias en torno

9 La utilización de la letra " $\mathrm{x}$ " tanto en este título como en otros a continuación y en diversas partes del texto tiene como objetivo no caer en una categorización de los actores y actrices abarcados asignando un apelativo genérico que tal vez no los identifique. Por lo tanto, utilizamos esta letra como forma de evitar una invisibilización a través del lenguaje.
Polemizar y controvertir lo incuestionable. Deconstruir conceptos estáticos mediante nuestra historia personal

Florencia Di Giorgio 

América Latina: género y política al título de veterano, sino también, respecto a su participación en la guerra como intersexual.

Como previamente comunicamos, Tahiana Marrone vivió casi la totalidad de su vida bajo una identidad impuesta por la cual se manifestaba y era percibida por su entorno como hombre. Como tal, tuvo que ir a la guerra sin siquiera haber desarrollado un cuerpo totalmente masculino (desde una perspectiva física y biológica), por lo cual batalló a la par del resto de los hombres sufriendo los achaques del conflicto con un cuerpo biológicamente "más" femenino que masculino. La misma Tahiana lo ha manifestado en diversas entrevistas, "cuando luché por la patria en la Guerra de Malvinas, ya me sentía mujer" (Marrone, 2016).

Esta participación en la guerra en un cuerpo cuyos rasgos biogenéticos tendieron a llevarla a desarrollarse fisiológicamente con características "más" femeninas que masculinas, nos lleva inevitablemente a preguntas que, lamentablemente, no he podido responder; cuestionándonos si aquello fue un obstáculo para relacionarse con el resto de sus compañeros, si se sintió diferente a ellos en algún momento, si tuvo que ocultar ya sea su cuerpo u oprimir actitudes para evitar generar alguna duda respecto a su masculinidad en un ámbito donde, supongo, las actitudes "varoniles" primaban y eran juzgados aquellos gestos asignados a lo femenino.

Junto a lo anteriormente nombrado, también debemos resaltar el hecho de que, con características fisiológicas de ambos sexos, Tahiana realizó en la guerra las mismas tareas que el resto de los conscriptos demostrando que no existe ninguna diferencia entre hombres y mujeres más que las construidas socialmente y que, si bien puede admitirse una mayor fuerza física de los cuerpos masculinos respecto a los femeninos, dicha diferencia no es sustento para marcar la superioridad de unos sobre otros, ni prohibir espacios o acciones apelando a la disparidad física de los mismos.

Resultaría sumamente enriquecedor poder reflexionar sobre cómo pudo haber sido atravesar un conflicto bélico en un cuerpo con características cruzadas de ambos sexos y las contingencias que debió atravesar a la hora de relacionarse con el resto de los excombatientes percibiéndose a sí misma como mujer, no obstante, esto será temporalmente inviable debido a la imposibilidad de contar con su testimonio directo respecto al tema. En lo que nos centraremos, entonces, será en intentar comprender cómo su intersexualidad implica una sacudida importante al estereotipo de "veterano de guerra", planteando la necesidad urgente de su redefinición y/o comprensión.

Como previamente manifestamos, el concepto de "veterano de guerra" es producto de una construcción colectiva a la que se suele asociar al hombre cisgénero heterosexual, cargando dicha identificación con todos los estereotipos propios de aquella etiqueta; el veterano de guerra, ya sea que se lo represente de manera valiente o temerosa, siempre se figuraba como un hombre, con rasgos viriles y de "macho" que puso su cuerpo al servicio de la patria. Por lo tanto, ni las mujeres que participaron de la guerra, ni Tahiana que hoy exterioriza 
su identidad femenina, calificarían con sus características y con los estándares que pesan sobre la categoría "mujer" como veteranas.

Porque si seguimos aquella línea marcada por el sistema androcentrista y heteronormado, la mujer es frágil, pasiva, dócil y servil al hombre; figuras que, si bien se fueron redefiniendo y cuestionando ya desde la segunda ola del feminismo, no dejan de ser reproducidas en la actualidad, y mucho menos lo eran hace 35 años cuando ocurrió la guerra y posteriormente cuando surgen los veteranos.

Tanto es así que en una entrevista dada por Tahiana a la periodista cordobesa Fabiana Dal Prá en abril del año 2018, la entrevistadora, siguiendo estos parámetros de roles marcados que previamente nombré, le pregunta si en la guerra "sintió la fortaleza del hombre o la fragilidad de la mujer", atribuyendo de esta forma un adjetivo a cada género en donde lo femenino es vinculado a la debilidad mientras que lo masculino es sinónimo de fuerza y valentía. Y no sólo esto, sino que la misma Tahiana responde siguiendo este hilo de ideas; ambas haciéndolo, seguramente, de manera inconsciente, pero demostrando cómo estamos ante una estructura cuyos preceptos se encuentran profundamente anclados en nosotros.

A lo que quiero llegar es, por un lado, a cómo el caso de un hombre que con el tiempo devino mujer es el ejemplo vivo de por qué no debemos encasillar en conceptos herméticos a nadie, entendiendo que las identidades son dinámicas y relacionales, no dadas ni construidas de manera invariable. Por el otro, debido a la fuerza que tienen aquellos conceptos en cuanto a su halo de inmutabilidad, no sería de extrañar que en muchos casos salieran personas a querer negar el papel de Tahiana en la guerra o justificar que ella no es la veterana de guerra, sino que quien lo es, es Osvaldo (quien ella solía ser), negándole a ella el "título" de veterana, siendo éste potestad exclusiva de Osvaldo.

En nuestro caso, lo que nos llama a reflexionar es la construcción en términos de masculinidad del concepto de veterano de guerra y cómo proceder ante el cambio producido de la persona que revestía el título. Ahora que Osvaldo pasó a ser Tahiana, ¿ya no podemos hablar de un veterano de guerra? O, en realidad, tal vez sí podamos hacerlo. Se trata aquí de una misma vida, una misma persona, pero de dos manifestaciones diferentes por las que ha atravesado su identidad de género que llevan a la necesidad de repensar uno de los roles que la identifican.

Por un lado, si tomamos la definición legal a partir de la cual se define al "veterano de guerra", oficialmente se considera que son excombatientes todo el personal de oficiales, suboficiales y soldados conscriptos, así como civiles que se encontraran cumpliendo funciones de servicios y apoyo en los escenarios T.O.M (Teatro de Operaciones de Malvinas) y T.O.A.S (Teatro de Operaciones del Atlántico Sur), esto sobre la base de los escenarios definidos por el gobierno militar argentino durante la guerra, y a la Ley $23.118^{10}$, sancionada ya durante la democracia sobre compensación a los veteranos.

${ }^{10}$ En esta ley, sancionada ya en democracia (1984) y posteriormente ampliada con sucesivas modificaciones, se dispone la condecoración mediante medalla y diploma a "los que lucharon
Polemizar y controvertir lo incuestionable. Deconstruir conceptos estáticos mediante nuestra historia personal

Florencia Di Giorgio 
Dossier América Latina: género y política
A la norma previamente nombrada se le debe sumar la ley 23.848 de 1990, modificada numerosas veces en años posteriores, siendo una de estas modificaciones la que dio lugar a la ley 24.343 de 1994 en donde se habla explícitamente por primera vez de los escenarios T.O.M y T.O.A.S. A partir de las mismas se elabora el concepto de "veterano" desde una perspectiva legal.

Siguiendo esta línea, Tahiana Marrone fue reconocida como veterano de guerra cuando su identidad exteriorizada era la de Osvaldo Marrone, dado que cumplía con todos los requisitos comprendidos en las correspondientes disposiciones. No obstante, y como se ha planteado a lo largo de todo el trabajo, entendemos que la definición de veterano no se agota en su dimensión legal, sino que ésta es una arista más dentro de la figura del veterano.

Por lo tanto, al poder distinguir múltiples factores que hacen a la totalidad de esta categoría es que sostenemos la conmoción que generan al mismo las distintas realidades que han surgido, interpelándolo desde diversos frentes. En el caso de Tahiana, su identidad de Osvaldo cumplía con todos los parámetros para ser reconocido como veterano, me refiero con ello a las determinaciones legales y la construcción sociocultural en torno a dicho rol. Pero el hecho de que ahora sea una mujer producto de un proceso de transición implica que, si bien desde el punto de vista legal continúa correspondiendo su reconocimiento dado que se adecúa a los términos planteados por la ley, socioculturalmente aún es muy temprano para hablar de un reconocimiento como veterana de guerra trans.

Y no sólo eso, lejos estamos de que, a la hora de figurarnos o describir a un veterano de la Guerra de Malvinas, nuestra asociación no vaya directamente a la construcción de un hombre cis heterosexual. Lo cual implica un peso para quienes buscan integrar este colectivo de veteranos al tener que llevar adelante la redefinición de todas aquellas características atribuidas a aquel título que no son representativas de su ser.

En cuanto a Tahiana, el peso más importante con el que tuvo que cargar y al que tuvo que enfrentarse es el de la asociación del rol sólo a un género, pero presentando un caso mucho más disruptivo y polémico que el de las mujeres debido a que la visibilización del colectivo trans implica una extensión en el tiempo mucho más acotada que el de las mujeres.

Producto de esta lucha más reciente en el tiempo en cuanto a la visibilización del colectivo trans, es que su integración y aceptación dentro de la sociedad todavía encuentra numerosas trabas que responden a una percepción imperante restringida de la identidad humana reproductora de la lógica binómica por la cual se "naturalizó" que la persona sólo puede ser hombre

en la guerra por la reivindicación territorial de las Islas Malvinas, Georgias y Sandwich del Sur, en las acciones bélicas del 2 de abril al 14 de junio de 1982" (Ley 23.118, 1984), determinándose que sólo el Ministerio de Defensa tiene la potestad de emitir dicho reconocimiento. Posteriormente esta ley fue modificada, hoy en día rige la Ley R - 1419 en la que se hicieron actualizaciones de forma que no cambian la esencia de la misma. 
o mujer, negando y censurando la pluralidad de subjetividades existentes respecto a la autopercepción personal.

Esta situación que, considero, implica el mayor impedimento para lograr una sociedad integrada y equitativa, se reproduce en el caso que tomamos debido a que, consecuencia de aquella tendencia a pensar el mundo de manera encasillada, caemos siempre en el intento de etiquetarlo todo y, en ese afán, lo hacemos buscando que aquello que deseamos etiquetar y el mote que queremos atribuirle se correspondan con parámetros de entendimiento manejables y comprensibles por uno mismo.

Cuando, a fin de cuentas, lo realmente importante no se encuentra en los títulos que intentemos poner, sino en aquello que la persona individual en cuestión quiera. Porque tal vez Tahiana continúe queriendo ser identificada como veterano de guerra, o tal vez prefiera que se la trate de veterana $\mathrm{o}$, incluso, apelar a un nuevo rótulo que la reconozca como excombatiente intersexual; solamente ella puede decidirlo, y sea cual sea su decisión, todas serán legítimas debido a que la transición que llevó adelante redefiniendo su identidad trasciende al rol que cumplió durante la Guerra de Malvinas.

Si bien este episodio es, seguramente, un hecho que marcó su vida, y bien ha remarcado que sobrevivir a la guerra tuvo una importante incidencia a la hora de tomar su decisión, es precisamente ella la que con su proceso lo redefine, y no la construcción hegemónica de una serie de conceptos (la idea de guerra y la de veterano) la que la determinan. Es ella quien, mediante sus decisiones y su comprensión personal del significado que tuvo participar de la Guerra de Malvinas, usó aquél acontecimiento de su vida como un impulso para aceptar y exteriorizar su verdadera identidad.

En lugar de restringirse a la representación predominante que pesaba sobre el veterano de guerra y dejar que aquello la determinara en su definición identitaria, invirtió este entramado, decidiendo anteponer su impronta personal al concepto. Es decir, utilizó aquel episodio traumático como motor positivo en lugar de dejarse reprimir por las normas que fueron construyéndose en torno a éste. Gracias a esto hoy podemos ver cómo es su identidad, la que está reclamándonos una redefinición del concepto, y no el concepto y sus restricciones que se está imponiendo.

Es así como hoy, acompañando las palabras de Tahiana, podemos decir que ella es una veterana de guerra, es decir que ha adoptado el título femenino para describir su status de haber combatido en la guerra de Malvinas. Toda la serie de posibles escenarios presentada en torno a las diferentes formas que podría tomar la definición de su participación en la guerra en función de su transición fue realizada con el objetivo de poder analizar y comprender la diversidad de casos que podrían presentarse, entendiendo que ninguno de ellos está "mal" siempre que se respete la voluntad del individuo.
Polemizar y controvertir lo incuestionable. Deconstruir conceptos estáticos mediante nuestra historia personal

Florencia Di Giorgio 
Dossier América Latina: género y política

\section{Cuestiones legales en torno al concepto de "veterano de guerra"}

Si bien hemos aclarado que el aspecto legal es tan sólo uno más de los componentes que inciden a la hora de considerar el concepto de "veterano de guerra", existe una realidad que no podemos negar y es que poseer un título convalidado legalmente en el que se es reconocido como veterano tiene una incidencia importante a la hora de lograr una aceptación social como tal debido a que, en muchos casos, la legalidad y la legitimidad suelen ir de la mano o bien la primera le otorga mayor envergadura a la segunda.

Las definiciones de este rol a partir de las sucesivas legislaciones nacionales ya han sido explicadas anteriormente y también hemos aclarado que Tahiana cuenta con el reconocimiento a nivel nacional como veterano de guerra debido a que éste le fue otorgado cuando era Osvaldo. Ahora bien, lamentablemente, aún se encuentra postergado su reconocimiento legal y sociocultural como veterana de guerra mujer, en entendimiento de que continúa siendo la misma persona, sólo que con una identidad de género diferente, siendo esta la única razón que motiva dicha dilación.

Aún en la nómina de veteranos de guerra presentada por el Ministerio de Defensa de la Nación, Tahiana sigue figurando como Osvaldo. No obstante, esta ausencia por parte del Estado Nacional comenzó a ser salvada en instancias previas: el Concejo Deliberante de la Ciudad de Córdoba reconoció el 11 de mayo de 2017 a Tahiana como excombatiente de la Guerra de Malvinas desde su identidad como mujer; de la misma manera, desde Chañar Ladeado (ciudad en la que vive) también extendieron un homenaje desde la comuna para reconocerla como veterana de guerra.

Por otro lado, y más complejo aún, es el hecho de que el Estado postergó la entrega a Tahiana de su Documento Nacional de Identidad y partida de nacimiento que reconocieran su identidad femenina. La Ley de Identidad de Género, número 26.743 establece claramente: "Art. $3^{\circ}$ - Ejercicio. Toda persona podrá solicitar la rectificación registral del sexo, y el cambio de nombre de pila e imagen, cuando no coincidan con su identidad de género autopercibida" (Ley 26.743, 2012). La misma ley ordena en su artículo sexto que:

Art. $6^{\circ}$ - Trámite. Cumplidos los requisitos establecidos en los artículos $4^{\circ}$ y $5^{\circ}$, el/la oficial público procederá, sin necesidad de ningún trámite judicial $o$ administrativo, a notificar de oficio la rectificación de sexo y cambio de nombre de pila al Registro Civil de la jurisdicción donde fue asentada el acta de nacimiento para que proceda a emitir una nueva partida de nacimiento ajustándola a dichos cambios, y a expedirle un nuevo documento nacional de identidad que refleje la rectificación registral del sexo y el nuevo nombre de pila... (Ley 26.743, 2012) 
Esta ley, sancionada el 9 de mayo de 2012, puso a nuestro país a la vanguardia en materia de legislación sobre género y diversidad sexual, convirtiéndonos en el único país, junto a Dinamarca, en contar con una ley en donde se determina que, con la sola manifestación expresa de la voluntad de la persona, ésta podía solicitar el cambio de su identidad de nacimiento para coincidir la misma con su identidad autopercibida. En cambio, otros países solicitan como requisito para ello algún diagnóstico psicológico o médico, como si la diversidad de género o sexual fuera algún tipo enfermedad o patología.

No obstante, las dificultades para las personas que llevan adelante una transición continúan a la orden del día; en el caso de Tahiana, habiendo iniciado el proceso de tramitación de una nueva partida de nacimiento a principios de 2017, para así poder obtener su DNI femenino, para abril de ese mismo año (4 meses después) el procedimiento se encontraba demorado.

Esto no sólo implica un perjuicio a la persona por la dilatación de un trámite que, si bien puede parecernos simple, para ella tal vez tenga un significado personal sumamente importante, sino que, además, representa un obstáculo importante debido que a que contar con un DNI que ratifique su nueva identidad es la puerta para que oficialmente el Estado argentino la reconozca como veterana femenina de la Guerra de Malvinas.

Esta postergación, tanto en la entrega de su DNI como a la hora de emitir el título que reconozca a Tahiana como veterana de guerra femenina, y así se la distinga en la nómina en donde oficialmente se agrupa a los excombatientes de Malvinas, puede ser considerada como parte de las tecnologías sociales, políticas y culturales que moldean al género denunciadas por Teresa de Lauretis (De Lauretis, 1980). En este caso, impuesta desde el aparato estatal, uno de los ámbitos reproductores del sistema patriarcal heteronormativo y cisexista más importantes debido a su alcance y penetración a la hora de crear instituciones aglutinadoras de la sociedad que adoptaron aquella lógica.

Esta dilación por parte del aparato estatal actúa como un mecanismo disciplinador que perpetúa aquellas prácticas machistas que buscaron ser rebatidas con las diversas leyes en materia de género y sexualidad pero que, no obstante, deben hacer frente a una estructura cimentada en bases profundamente arraigadas.

Poder lograr este objetivo será fundamental en pos del reconocimiento de la transición llevada adelante por Tahiana, y significará un instrumento sumamente importante para legitimar su rol de veterana de guerra. Digo esto debido a que una política pública directa por parte del Estado, en muchos casos, tiene la potestad de generar un efecto ejemplificador y dotar de legitimidad alguna cuestión sólo por ser legalmente admitida. Su aceptación como excombatiente femenina significa el reconocimiento total de sus derechos como mujer en todos los ámbitos de su vida, así como de su identidad femenina en los mismos; y al emanar este reconocimiento del Estado, Tahiana contaría con un apoyo más, y sumamente fuerte, para ser aceptada como mujer y veterana a nivel social.

Sería conveniente que el Estado en sus diferentes niveles promueva políticas públicas que permitan visibilizar el caso de Tahiana. Por un lado, porque
Polemizar y controvertir lo incuestionable. Deconstruir conceptos estáticos mediante nuestra historia personal

Florencia Di Giorgio 
Dossier América Latina: género y política la difusión de su historia y el conocimiento de la misma facilitaría la aceptación de su figura como intersexual a nivel social, pero además porque sería una forma de extender el debate que hoy existe respecto a los roles impuestos socioculturalmente sobre lo femenino y lo masculino, planteando un caso sumamente disruptivo tanto porque cuestiona la construcción hegemónica que la sociedad argentina tiene sobre el veterano de guerra de Malvinas, pero también porque se sale de la perspectiva predominante desde la cual se suele plantear dicho debate. Me refiero a que usualmente el cuestionamiento de los roles se plantea desde el binomio hombre - mujer, invisibilizando a una gran parte de la comunidad como son todas aquellas identidades que no responden a la heteronormatividad. Por eso el caso de Tahiana plantea una ruptura desde muchas perspectivas e invita a reflexionar la construcción sociocultural de la identidad sexual y de género en sí, y no sólo de los estereotipos de lo femenino y lo masculino.

\section{El impacto de una veterana intersexual en la sociedad}

Desde que nació, y a lo largo de toda su crianza, a Tahiana se le impusieron tanto el sexo como el género masculino. A raíz de dicha identidad construida en respuesta a normas ajenas, la cual no se correspondía con aquella autopercepción sobre sí misma que tendía a identificarla con el género femenino, Tahiana tuvo que participar de la Guerra de Malvinas en cumplimiento activo de un rol asignado casi exclusivamente a lo masculino (a pesar de que el devenir histórico ha demostrado que la guerra dista mucho de ser un monopolio de los hombres).

Esto ha conllevado a que, producto del viraje que tomó su vida cuando hace unos años decidió llevar adelante la transición para representarse como mujer, pasara a convertirse en la primera excombatiente transexual, produciéndose así una colisión respecto a dos partes constitutivas sumamente importantes de su ser.

Por un lado, Tahiana es parte de un colectivo sobre el cual pesa un desconocimiento generalizado y que fue víctima y aún lo es de discriminación, negación y violencia como son los transexuales y, además, los intersexuales ${ }^{11}$; pero a la vez, es miembro de un grupo sumamente legitimado, respetado y admirado por gran parte de la sociedad argentina, al punto de que se los ha catalogado con el título de "héroes" y ocupan hoy (luego de años de lucha y esfuerzos) un lugar incuestionable en nuestra sociedad, como son los veteranos de la Guerra de Malvinas. Así pues, en ella colisionan dos atributos de

11 Recordemos que Tahiana es una mujer reconocida como tal producto del proceso de transición de su sexualidad. Decisión que tomó cuando finalmente encontró las respuestas a aquellas pulsiones femeninas que tuvo a lo largo de toda su vida al conocer que posee el Síndrome de Klinefelter por el cual pertenece, además, al colectivo intersex. 
su identidad, uno invisibilizado y estigmatizado, y el otro reivindicado y exaltado. $\mathrm{O}$, más bien, podríamos decir que no son los atributos de su identidad los que colisionan, sino la aprehensión y comprensión sociocultural que pesa sobre cada uno de ellos.

Para nosotros, entonces, la historia de Tahiana representa el ejemplo vivo de cómo las etiquetas no responden más que a estereotipos cargados de significados construidos socioculturalmente, porque ¿cómo es que en la misma persona pueden convivir dos rasgos de una misma identidad, siendo una enaltecida mientras que la otra fue continuamente postergada y relegada? Esto es así por el simple hecho de que, mientras una de esas manifestaciones identitarias está socialmente legitimada y, además, es reivindicada, la otra recién está comenzando el camino de ser comprendida y aceptada.

Además, este camino emprendido implica atentar en contra de una estructura construida a la par misma que la sociedad humana, es decir, significa cuestionar la lógica que en su totalidad ha marcado la evolución de la convivencia comunitaria a partir de la cual se reproduce de antaño la dialéctica androcentrista, heteronormativa y binaria que hemos venido denunciando en este trabajo y que, como tal, penetra en todas las instituciones, redes y ámbitos de la vida.

Esta estructura produjo categorías construidas para clasificar a las personas, presentándose desde siempre como inalterables e incuestionables y, así, calaron profundo tanto colectiva como individualmente en cada persona. De esta manera es que inconscientemente reproducimos ideas, muchas veces sin cuestionarlas, como es la de asociar a los veteranos de guerra únicamente con hombres.

A raíz de esto, podría animarme a vaticinar que para muchos la transición de hombre a mujer de un veterano de guerra significó una pérdida de legitimidad de este último título, debido a que ya no responde al estereotipo unívoco socialmente construido y aceptado de que los veteranos de la guerra de Malvinas son hombres cis y heterosexuales. O bien puede suceder que realicen una división en la cual se reivindique la participación de Osvaldo en la guerra y su heroicidad, separándolo de la identidad de Tahiana.

También están quienes en ella no ven a una mujer, sino que sostienen que sigue siendo el mismo hombre, pero "disfrazado", de manera que continúan reproduciendo mediante la imposición, la negación y la humillación a su decisión personal, la lógica binaria y cisexista de antaño. Esta situación, además de manifestar importantes niveles de violencia al desconocer la identidad manifestada por la persona en cuestión y buscar imponer márgenes de entendimiento y existencia restringidos acordes a las percepciones (limitadas) propias de quien juzga, significa nuevamente el intento de encasillar la comprensión del concepto de "veterano de guerra" desde aquella visión actualmente imperante que no sólo no ampara a quienes no responden a los cánones determinados por el mismo (caso mujeres), sino que también llega a expulsar a quienes, si bien en un momento sí lo hacían (caso Tahiana), producto de su transición, ya no.
Polemizar y controvertir lo incuestionable. Deconstruir conceptos estáticos mediante nuestra historia personal

Florencia Di Giorgio 
Dossier América Latina: género y política
No obstante, debemos rescatar lo positivo de la coyuntura que estamos viviendo. Hoy nos encontramos atravesando por un momento histórico en el que se ha vuelto aún más generalizado el cuestionamiento a la visión hegemónica de carácter binómica, androcentrista y heteronormada del ser humano y, en consecuencia, de la sociedad en general. La difusión que ha permitido el desarrollo tecnológico, así como los diferentes medios de comunicación y las redes sociales de una comprensión del mundo más integradora y respetuosa del otro, ha logrado que esto cale cada vez más profundo y se difunda con una masividad casi sin precedente.

Gracias a esto, de la misma manera que nos encontramos con grupos reaccionarios que niegan las identidades no binarias, también existe un movimiento cada vez más grande y, fuera de este, una gran cantidad de individuos dispuestos a aceptar aquellas realidades que antes hubieran negado. Por eso, cuando Tahiana pasó a ser veterana de la Guerra de Malvinas, dejando atrás su pasado como veterano, se encontró con algunos compañeros que aceptaron dicha transición y aquello no implicó jamás ubicarla en un plano de inferioridad debido a que, en esencia, Tahiana siempre fue, es y será la misma persona, aquella que luchó a su lado, con el mismo ímpetu y valentía.

También llegaron a Tahiana reivindicaciones desde distintos ámbitos de la sociedad, habiendo sido invitada en el año 2017 para ser reconocida con su nombre por la escuela Hipólito Yrigoyen de su ciudad natal, o cuando desde Chañar Ladeado extendieron para ella una placa en reconocimiento con el nombre de Tahiana Marrone. Gracias a esto, su historia es cada vez más conocida. Hoy se encuentra contándola en diversos medios tanto provinciales como nacionales, convirtiéndose así en una referente para otros y otras intersexuales que buscan comprender su situación. Una responsabilidad que ha decidido asumir y por lo que realiza diversas charlas sobre orientación sexual, identidad de género y, más importante, para quienes tengan dudas y dificultades a la hora de aceptar su identidad autopercibida cuando esta no responde a los estándares hegemónicos.

\section{Tensiones internas dentro del espectro de veteranx hombre - intersexual - mujer}

A lo largo de este trabajo se ha planteado el objetivo de deconstruir el concepto de "veterano" que se erige hoy como hegemónico y, como tal, expulsa o descalifica a quienes no cumplen con los parámetros planteados por aquél. A raíz de este propósito proyectado hemos buscado desagregar dicho concepto para comprender a los diferentes actores y actrices que pueden conformarlo cuando relativizamos los preceptos que en su momento fueron impuestos como unívocos y estancos.

De esta manera sucede que, cuando abrimos el espectro de veterano / veterana de guerra podemos ubicar en un extremo a los veteranos masculinos, quienes 
cumplen con todas las premisas que los legitiman como tales (legales, sociales, culturales), y en el otro extremo encontraremos a las mujeres que están llevando adelante un proceso de deconstrucción y reconstrucción con redefinición del concepto, una tarea sobre la cual subyace el objetivo de lograr el reconocimiento postergado que como veteranas de la guerra merecen. Una tarea, a su vez, que ha permitido reconocimientos diversos (algunas cuentan con reconocimientos legales y otras no), pero en donde el reconocimiento social aún se encuentra lejos de ubicarlas a la par con los excombatientes masculinos.

Ahora bien, si continuamos haciendo foco en este espectro que hemos abierto sobre los y las veteranas, nos encontraremos en el centro del mismo con Tahiana Marrone. Su caso la ubica en este lugar en donde se produce una pendulación entre cada extremo debido a que, más allá de que su vida en sí implique una transición cuando nos referimos a su identidad de género, también lo es su carácter de veterana / veterano de la Guerra de Malvinas (hablando desde el punto de vista del reconocimiento).

Sucede que, y como lo hemos remarcado anteriormente, como Osvaldo poseía aquel reconocimiento a la par del resto de los excombatientes hombres, su rol era legitimado como tal, pero, al llevar adelante su transformación para exteriorizar su verdadera identidad femenina, se hace presente un fuerte interrogante en torno a cómo comprender aquella parte de su identidad como excombatiente desde su nuevo género. ¿Cómo puede dejar de ser legítima su participación en la guerra y reconocimiento como veterana si estamos hablando de la misma persona?

Es precisamente en este punto cuando se hacen presentes y más visibles que en cualquier caso las dificultades que imponen a la comprensión el marco restringido de entendimiento que nos brinda una estructura tan encasillada como es el sistema patriarcal bajo su lógica binaria, porque a pesar de tratarse de una misma realidad, el proceso de su reconocimiento no se plantea tan simple.

Además, el caso que aquí nos llama a reflexionar también supone una tensión respecto al reclamo esbozado por las mujeres de la guerra, debido a que Tahiana reúne, a partir de su transición, todas las características que responden al concepto legitimado de veterano y, además, la particularidad de que su género ahora es femenino. Por lo tanto, desde su pasado como Osvaldo y desde su presente como Tahiana su ser agrupa todos los rasgos a partir de los cuales las veteranas mujeres intentan ser reconocidas.

No obstante, Tahiana logra aglutinar todos estos atributos debido a que, tanto en el inconsciente colectivo como en los parámetros legales, continúa primando la percepción masculina del rol de veterano, de manera que, a pesar de su transición, se superpone la comprensión androcentrista del concepto y de su ser a partir de la cual se impone la legitimidad de su rol como veterano, por sobre el reconocimiento como veterana femenina.

A lo que me refiero es a que, si bien Tahiana hoy exterioriza una identidad de género femenina, la cual la acerca más a las veteranas de la guerra, a la hora de analizar su reconocimiento nos encontramos con que los parámetros
Polemizar y controvertir lo incuestionable. Deconstruir conceptos estáticos mediante nuestra historia personal

Florencia Di Giorgio 
Dossier América Latina: género y política estándares que se toman continúan siendo los que responden al concepto hegemónico de la lógica heteronormada y cisexista. Si se la considera veterana, se lo hace porque se la figura como el veterano que fue.

A raíz de aquello, tanto para las mujeres de la Guerra de Malvinas, como para Tahiana quien ahora también es una mujer de la Guerra pero que participó de la misma como soldado, permanece la "vara de medición" de su rango de "veteranas" en torno a cuánto cumplan o no con los criterios que hacen al "veterano de la Guerra de Malvinas", en lugar de avanzar a otro nivel en donde se flexibilice aquel concepto y se lo redefina de acuerdo con las diferentes realidades que implican cada uno de los y las participantes que buscan ser amparados por el mismo.

$\mathrm{Y}$ es producto de aquella comprensión imperante que se perpetúan y reproducen prácticas discriminatorias tanto para las mujeres del cuerpo sanitario como para Tahiana, quien hoy sigue figurando en la nómina de excombatientes como Osvaldo y, fuera de lo legal, trasladándonos a la esfera sociocultural, continúa remarcándose su identidad masculina a la hora de referirse a ella como veterana.

Previamente he hablado de esto y vuelvo a traerlo debido a que muchos excombatientes también han sido agentes reproductores de aquello; me refiero a que muchos ven en ella a un "hombre disfrazado" en lugar de una mujer, de manera que -al anular su identidad femenina, alegando que es un hombre vestido con "ropas de mujer"- lo que están haciendo es reafirmar la posición patriarcal de que allí no existe ninguna veterana, sino que continúa siendo el veterano de guerra masculino, es decir, han adaptado la comprensión de la transición llevada adelante por Tahiana a su marco restringido de comprensión, tomando una posición discriminatoria y siendo ejemplo de cómo actúan los dispositivos moldeadores de la identidad.

Estos casos disruptivos que se han presentado generan tensiones inherentes que no sólo interpelan el concepto hegemónico de "veterano de guerra" que ellos encarnan, sino que, además, los ataca directamente a ellos en una parte constitutiva de su identidad muy importante. Un aspecto de ésta que construyeron dotándola de un rasgo clave que es la masculinidad; bajo la idea de haber puesto el cuerpo enfrentándose, a pesar de todo, con el enemigo, creándose así un halo de virilidad y valentía al que las mujeres no pueden entrar, perpetuando así aquella construcción simbólica de la hombría propia de los contextos bélicos.

Si tomamos la definición de identidad tal como la conciben Tajfel y Turner (1986) desde el enfoque de la construcción social de la misma, la entenderemos como „aquellos aspectos de la propia imagen del individuo que se derivan de las categorías sociales a las que percibe pertenecer" (p. 16). A partir de esta base que nos otorga la teoría de la identidad social, y si seguimos lo proyectado por la misma según la cual la identidad tiene tres componentes claves que son la categorización, la identificación y la comparación, podremos comenzar a entender el fuerte anclaje que debe significar 
para los veteranos de la Guerra de Malvinas el identificarse y ser reconocidos socialmente como tales.

Por lo tanto, si se redefine aquel concepto imperante ¿también estamos redefiniendo la identidad de quienes se identificaban con el mismo? ¿Sentirán un ataque directo a su masculinidad? Como podemos ver, inmediatamente entra en acción aquella mentalidad androcentrista que tan naturalizada se encuentra, en la que el hombre cis heterosexual se convierte en el centro alrededor del cual debe ser definida la realidad que lo circunda. Es decir, tanto las mujeres que estuvieron en la guerra, constituyendo parte del cuerpo sanitario, como Tahiana -que ahora es una mujer-, deben ingeniárselas para buscar un lugar dentro del concepto hegemónico que aquí cuestionamos, en lugar de plantearse una redefinición del mismo que ampare a todos.

El hombre, nuevamente, vuelve a ser el significante respecto al cual se le otorga entidad al resto de las cosas. En consecuencia, al hacerse presentes realidades que los cuestionan, inmediatamente muchos toman una actitud reaccionaria y negacionista producto de una creencia errónea de que la totalidad de su identidad será redefinida y cuestionada, siendo esto una consecuencia del entrecruzamiento y confusión personal en la que caen al definir la totalidad de su identidad de acuerdo con un rol (construido y, por lo tanto, pasible de ser cuestionado y redefinido).

Por lo tanto, permanecen en una postura inflexible y defensora del status $q u o$, amparados por una estructura que los respalda y reproduce aquella comprensión restringida, a la vez que legitima aquel aspecto casi consustancial a su identidad en torno al cual se cimentó un rol planteado como inalterable. Además, estos individuos han construido en torno a él "su autoestima y organizan el mundo social [mediante] dicho pensamiento categorial" (Dovidio y Gaertner, 1999). Es decir, parte no despreciable de su entidad y posicionamiento sociocultural, el cual les ha traído reconocimiento social y ha permitido que parte de su autoestima se potencie, es gracias a aquella visión hegemónica sostenida sobre el veterano de guerra que se plantea como un monopolio de quienes acusan dicho título.

Y, precisamente, los estereotipos de género se convierten en una herramienta más para actuar en contra de quienes demandan ser reconocidas bajo este título, adoptándose la clásica estrategia en la cual se penaliza a quienes se desvían del comportamiento socialmente esperado. Tal como sucede cuando a Tahiana se la desacredita, alegando que sólo es un hombre con ropas femeninas, o cuando a las mujeres del cuerpo sanitario se las insulta o no se las invita a los desfiles en homenaje a los veteranos; actitudes de las cuales se desprende el objetivo de disciplinar los cuerpos y subjetividades de quienes se han atrevido a cuestionar el concepto androcentrista y cisexista de "veterano de guerra" y, así se están enfrentando, de trasfondo, a toda la estructura patriarcal que lo sostiene y lo ampara, haciéndolo en reclamo por una visibilización de su historia y por lograr ser ubicadas en un plano equitativo con los hombres.
Polemizar y controvertir lo incuestionable. Deconstruir conceptos estáticos mediante nuestra historia personal

Florencia Di Giorgio 
Dossier

América Latina: género y política

\section{Conclusiones}

Cuando intentamos llevar adelante el desafío de comprender un mundo tan diverso como es el de la diversidad sexual y de género, en donde las herramientas tomadas han sido producidas hace relativamente poco tiempo, es casi inevitable caer en errores involuntarios. Tal vez a lo largo de este trabajo pude haber aplicado conceptos equivocadamente, o incurrí en errores gramaticales sin saber cómo comprender determinadas categorías; no obstante, acepto que esto pudo haber pasado y por ello busco aprender y abrir mi mente para que la misma pueda comprender y aprehender todas estas realidades para evitar caer en una invisibilización y negación de las mismas a la hora de expresarme respecto a ellas.

Este primer párrafo de reflexión personal que abre la conclusión del presente trabajo busca ser un llamado a todas las personas a iniciar su propio proceso personal reflexivo para lograr entender que las verdades que damos por sentadas tal vez no sean tan incuestionables como creíamos y, como seres humanos, nada nos hace crecer más que polemizar sobre aquello que nos fue presentado como un dogma inapelable. Si no debatimos sobre nosotros mismos, sobre quiénes somos, cómo percibimos a los demás, cómo nos relacionamos, únicamente terminaremos por vivir una vida estancada donde nuestra visión sobre lo que nos rodea será sumamente limitada.

La realidad que nos circunda es tan mutable y diversa que nos llama constantemente a pensarla, a generar nuevos conceptos para explicarla y así avanzar. Quedarnos en aquella perspectiva anquilosada de que un ser humano sólo puede ser hombre o mujer no sólo significa reducirnos a una visión meramente físico-biológica, sino que, además, es negar la existencia misma de tanta gente que nos rodea, es convertirnos en agentes de su invisibilización y centinelas de algo tan personal y subjetivo como es la identidad de género, negando parte de su ser y despojándolos de entidad sólo por el empecinamiento de no querer salir del mundo estático que se nos enseñó.

No obstante, existen muchas personas que estuvieron y están dispuestas a realizar aquel proceso de cuestionamiento personal, entendiendo que no debe ser dado por sentado todo aquello que me fue enseñado, menos aun cuando esto fue en el marco de una estructura directriz cuya naturaleza plantea la dominación de un grupo de seres humanos (hombres cis heterosexuales) sobre el resto de las categorías sexuales y de género humanas existentes (mujeres, gays, lesbianas, transexuales, bisexuales, intersexuales, queer, etc.).

A raíz de esto han aparecido nuevas premisas más inclusivas que nos permiten comprender que sexo no es lo mismo que identidad de género, género no es lo mismo que orientación sexual, y orientación sexual no es lo mismo que expresión de género. Y a raíz de estos cuestionamientos generados hemos podido avanzar en la deconstrucción de las diversas representaciones cuyo andamiaje respondían a esta estructura anquilosada, de manera que muchos han dejado de ver como necesario aquel correlato en el que se atribuían roles 
sociales al género, ubicando entre ellos la percepción de que la guerra y el ser veterano de la misma implicaba un monopolio masculino.

En este marco, Tahiana es un ejemplo vivo que nos obliga a comprender que un mismo ser humano pudo haber sido veterano para luego convertirse en veterana, demostrando cómo el ser humano nunca puede ser entendido bajo conceptos invariables porque una misma vida puede implicar cambios tan disruptivos como este.

Por lo tanto, nada está dado, nada permanece inmutable en el tiempo, lo importante será saber adaptarse a aquellos cambios para no caer en la invisibilización de quienes llevan a cabo los procesos de redefinición de su autopercepción personal y exteriorización de la misma, a la vez que en dicho proceso, tal vez inconscientemente, emprenden la acción de interpelar y deconstruir todo un entramado androcentrista y sexista como es, en este caso, el que rodea al concepto de "veterano de la Guerra de Malvinas".

Una tarea en la que se encontrarán con el constante cuestionamiento a su identidad, y el ataque por parte de quienes no pueden ver más allá de su perspectiva personal de comprensión de la realidad pero, también, por parte de quienes tienen un fuerte arraigo con dicho concepto al punto que el mismo se ha convertido en parte constitutiva de su identidad y, por lo tanto, se definen en torno a él, de manera que aquellas realidades que lo cuestionan significan una alteración imposible de aceptar.

Los niveles de negación de alguien cuyas verdades están siendo cuestionadas por la realidad que atraviesa por sus ojos pueden llegar a puntos difíciles de imaginar. $\mathrm{Y}$ es que cualquier argumento, por más banal y vacío que suene, será más lógico para ellos que la simple idea de aceptar una verdad que responda a criterios contrarios a los que predican; porque hacerlo significaría, por un lado, una herida al orgullo, teniendo que aceptar la equivocación propia, por otro lado, tener que cuestionar todo un andamiaje de pensamiento construido a lo largo de la vida y, finalmente, como venimos aduciendo, cuestionar la identidad propia, tener que redefinir, o al menos preguntarnos, quién soy yo en cuanto a las percepciones que tengo respecto a quienes me rodean, o hasta redefinir quién soy en vista de las nuevas formas de ser que antes me eran ajenas.

No pretendemos plantear la súbita y necesaria desvinculación del concepto de "veterano de guerra" de la categoría de hombre cis heterosexual. Al contrario, lo que sostenemos es la urgencia de ampliar la percepción de dicho rol en una definición de alcance socioculutral generalizado que no se acote sólo a una perspectiva androcentrista y cisexista que nos lleve a caer involuntariamente en una representación unívoca del término. Pretendemos una redefinición inclusiva que permita amparar, reconocer y visibilizar las diversas realidades que pueden ser incluidas dentro de este término, entre ellas, una veterana trans y mujeres veteranas.

Y así lograr, tal vez algún día, una deconstrucción tal del concepto que a la hora de pensar en los y las veteranas de la Guerra exista una figuración de su prototipo que no caiga directamente en el género masculino, sino que pueda
Polemizar y controvertir lo incuestionable. Deconstruir conceptos estáticos mediante nuestra historia personal

Florencia Di Giorgio 
Dossier América Latina: género y política pensarse en primera instancia en una veterana de guerra. Para ello, lo primero que debemos lograr es visibilizar y legitimar el rol de las veteranas, así como también despojar este estereotipo de atribuciones relativas al género a la hora de llevar adelante la configuración del mismo.

Para lograr esto, será imperante que las personas y la sociedad en general puedan romper con aquel pensamiento circunscripto a la idea binómica del género que, en palabras de Butler, "reduce la posibilidad de pensar en su alteración" (2004, p.71).

A fin de cuentas, todo dependerá de cuán permeables seamos a comprender que la verdad es, más bien, subjetiva. Si logramos aprehender esto, entonces abriremos las puertas a la comprensión de que la misma puede ser desarmada para construir sobre sus cimientos una nueva, con nuevas pautas que legitimen novedosas formas de relacionarse con los demás y de percibirse a uno mismo. Esto significará no sólo cuestionar el rol del hombre y de la mujer y los estereotipos socioculturales impuestos sobre cada uno de ellos, sino llevar adelante una deconstrucción total de los mismos y comprender que las identidades en términos de sexualidad y género van mucho más allá de este binomio, como Tahiana y su transición nos han demostrado.

El movimiento feminista actual tal vez sea el más indicado, junto al colectivo LGBTIQ+, para llevar adelante estos cambios (como históricamente vienen haciendo). No obstante, si bien está encarando una lucha en muchos frentes, adolece de una cuestión que es el excesivo centralismo puesto sobre la mujer. Siendo hoy el movimiento capaz de aglutinar y representar a todas las identidades invisibilizadas y excluidas socialmente que son víctimas constantes del sistema patriarcal y sobre las cuales pesan estereotipos y etiquetas que deben ser deconstruidos, este movimiento debería siempre buscar ser cada vez más abarcativo e inclusivo.

Entendiendo que hoy en día es el movimiento que posee el potencial de representar a un colectivo aún mayor que sólo el de las mujeres y que, respondiendo al objetivo que en esencia le dio origen, como es el poner fin a la dominación patriarcal (que oprime a toda persona que no sea hombre cis heterosexual) es el más pertinente para llevar esta lucha adelante en nombre de todos los subyugados por este sistema.

\section{Referencias bibliográficas}

Argentina.gob.ar (2017). La I en LGBTIQ: ¿Quéesla Intersexualidad? Recuperado 20.05.2018 de https://www.argentina.gob.ar/noticias/la-i-de-lgbtiq-que-es-la-intersexualidad

Berger, P. y Luckmann, T. (1968). La Construcción Social de la Realidad. Buenos Aires: Amorrortu Editores.

Bourdin, J-C. (2010). La invisibilidad social como violencia. En línea. Recuperado 06.06.2018 de http://www.scielo.org.co/scielo.php?script=sci_arttext\&pid=S0120-53232010000100002

Butler, J. (1993). Cuerpos que importan. Sobre los límites materiales y discursivos del "sexo". Buenos Aires: Editorial Paidós. 
Butler, J. (1999). El género en disputa. El feminismo y la subversión de la identidad. Buenos Aires: Editorial Paidós.

Butler, J. (2004). Deshacer el género. Buenos Aires: Editorial Paidós.

Cabral, M. (2012). Entrevista a un activista intersexual. Corporación Femm. Recuperado 20.05.2018 de http://www.corporacion-femm.org/index.php/noticias/noticias-mundiales/311entrevista-a-un-activista-intersexual.html

Dovidio, J. F., Gaertner. S. (1999). Reducing Prejudice: Combating Intergroup Biases. Current Directions in Psychological Science, vol. 8, issue 4. Recuperado 25.08.2018 de https://journals.sagepub.com/doi/10.1111/1467-8721.00024

Fernández, J. (2005). La noción de la violencia simbólica en la obra de Pierre Bourdieu: una aproximación crítica. Cuadernos de Trabajo Social, no. 18, pp. 7-31. Recuperado 06.07.2018 de http://www.enlinea.cij.gob.mx/Cursos/Hospitalizacion/pdf/PierreBourdieu.pdf

Foucault, M. (1975). Vigilar y Castigar. Nacimiento de la Prisión. Argentina: Editorial Siglo Veintiuno.

Ley 26.743. (2012). Ley de Identidad de Género. Recuperado de http://servicios.infoleg.gob. ar/infolegInternet/anexos/195000-199999/197860/norma.htm

Marrone, T. (2017). XXY: fue a luchar a Malvinas y ahora pelea para que la acepten como mujer. Diario Clarín. Recuperado 19.05.2018 de https://www.clarin.com/sociedad/excombatiente-malvinas-lucha-aceptada-mujer_0_BJm2iR1ag.html

Marrone, T. (2017).Lahistoria de Tahiana, la chica trans que combatió en Malvinas. BigBangNews. Recuperado 18.05.2018 de https://www.bigbangnews.com/actualidad/La-increible-historia-deTahiana-la-chica-trans-que-combatio-en-Malvinas-como-soldado-20170403-0041.html

Marrone, T. (2018). Entrevista realizada por Fabiana Luz Dal Prá para el Canal C (12) de Córdoba.

Ministerio de Defensa de la Nación (s.f.). Nómina de Veteranos de Guerra de Malvinas. Recuperado 20.08.2018 de http://www.veteranos.mindef.gov.ar/listados/ejercito/1

Preciado, P. B. (2002). El Manifiesto contrasexual. Madrid: Editorial Opera Prima.

Rich, A. (1980). La heterosexualidad obligatoria y la existencia lesbiana. Nueva York: W.W. Norton \& Company.

Tajfel, H. y Turner, J.C. (1986). The Social Identity Theory of Intergroup Behaviour. En S. Worchel, W. G. Austin (Eds.). Psychology of intergroup relations (pp. 7-24). Chicago, IL: Nelson-Hall Publishers.
Polemizar y controvertir lo incuestionable. Deconstruir conceptos estáticos mediante nuestra historia personal

Florencia Di Giorgio 